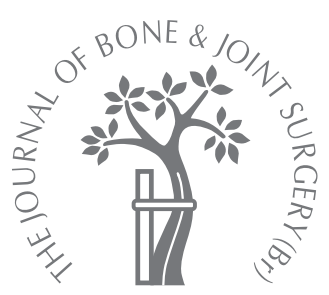

J. H. M. Goosen, C.C.P.M. Verheyen, N. J. A. Tulp

From Weezenlanden Hospital, Zwolle, The Netherlands
J. H. M. Goosen, MD, Resident Orthopaedic Surgery

C. C. P. M. Verheyen, MD, PhD, Orthopaedic Surgeon N. J. A. Tulp, MD, PhD, Orthopaedic Surgeon Department of Orthopaedic Surgery

Isala Clinics, Weezenlanden Hospital, 8011 JW Zwolle, The Netherlands.

Correspondence should be sent to Dr N. J. A. Tulp; e-mail: n.j.a.tulp@isala.nl

(C)2005 British Editorial

Society of Bone and

Joint Surgery

doi:10.1302/0301-620X.87B11.

$16101 \$ 2.00$

$J$ Bone Joint Surg [Br] 2005;87-B:1475-9.

Received 22 October 2004;

Accepted after revision

18 May 2005

\title{
Mid-term wear characteristics of an uncemented acetabular component
}

We investigated the rate of polyethylene wear of a cementless acetabular component at different periods of follow-up in order to test the hypothesis than an irrecoverable deformation process (creep) was followed by an initially low, but gradually increasing wear rate. We studied prospectively 93 uncemented total hip arthroplasties in 83 patients (mean age 50 years (22 to 63 )) with a mean follow-up of 8.2 years (3 to 12). We measured the penetration of the femoral head from radiographs taken immediately after surgery at three, six and nine years, or at the latest follow-up.

The median wear rate was $0.17 \mathrm{~mm}$ per year in the first three years, a finding which we considered to be caused by creep. Thereafter, the rate of wear declined to $0.07 \mathrm{~mm}$ per year (four- to six-year period) and then increased to $0.17 \mathrm{~mm}$ per year (seven to nine years) and $0.27 \mathrm{~mm}$ per year (more than nine years), which we considered to be a reflection of genuine polyethylene wear. After the nine-year follow-up the wear rates were higher in patients with marked osteolysis. We found no relationship between the inclination angle of the acetabular component or femoral head orientation and the rate of wear. No acetabular component required revision.

In the early years of total hip arthroplasty (THA), component loosening was considered to be the main cause of failure ${ }^{1}$ while now, polyethylene wear leading to osteolysis is regarded as the main issue. ${ }^{2}$ The survival of prostheses depends on factors which influence the rate of polyethylene wear. ${ }^{3}$ The effect of implantation time on the rate of wear has been investigated by several authors, albeit with different results. ${ }^{4-8}$ Deformation of polyethylene (creep) can occur after THA, so our aim was to test the hypothesis that polyethylene creep in the first years after implantation is followed by an initially low but increasing, genuine polyethylene wear.

\section{Patients and Methods}

Between 1992 and 1996, we implanted 122 primary uncemented THAs in 109 patients. Bilateral operations were undertaken in 13 of these patients. During the follow-up period 14 patients died from unrelated causes, and ten were lost to follow-up. In addition, one femoral stem had subsided for more than $2.5 \mathrm{~cm}$ because of fissuring of the calcar, and another developed early deep infection; both underwent early revision. A total of 29 THAs $(26$ patients) was excluded, leaving 93 THAs (83 patients) with adequate clinical and radiographic follow-up (Table I).
During this time period, a Mallory (Biomet, Warsaw, Indiana) acetabular shell was used. This was multi-holed until 1994 and threeholed thereafter $(44 \%$ vs $56 \%$ of THAs, respectively). It is hemispherical, with a titanium porous coating and has four peripheral fins providing rotational stability. A Ringloc (Biomet) compression-moulded ultra-high-molecular-weight polyethylene (UHMWPE) liner was used. In all patients, a Bi-Metric (Biomet) titanium alloy, proximally hydroxyapatitecoated femoral component, with a cobaltchrome, 28-mm femoral head (Biomet) was also used. Additional acetabular screws were used in nine hips. Systemic, prophylactic antibiotics (cefazolin $2 \mathrm{~g}$ intravenously) and pharmacological thromboprophylaxis were used, initially fraxiparine 2850 IU subcutaneously followed by acenocoumarol up to three months post-operatively.

Patients with a minimum follow-up of three years were included in this study and were clinically evaluated pre-operatively and then postoperatively at six weeks, three and six months, at one year and annually thereafter. The Harris hip score 9 (HHS) was monitored at each visit. Radiographic analysis. We evaluated the pelvic anteroposterior (AP) and lateral hip radiographs which had been taken immediately 
Table I. Characteristics of the 83 patients (93 total hip arthroplasties)

\begin{tabular}{ll}
\hline Gender & \\
\hline Gender (\%) & $36(43)$ \\
$\quad$ Men & $47(57)$ \\
$\quad$ Women & $1.73(1.53$ to 1.90) \\
Height in m (range) & 82 (55 to 123) \\
Weight in kg (range) & $27(19$ to 41$)$ \\
Body mass index (range) & $50(22$ to 63) \\
Age at operation in yrs (range) & $8.2(3$ to 12) \\
Mean follow-up in yrs (range) & \\
Pre-operative diagnosis in number of hips (\%) & $67(72)$ \\
$\quad$ Osteoarthritis & $14(15)$ \\
$\quad$ Osteonecrosis & $5(5)$ \\
$\quad$ Rheumatoid arthritis & $5(5)$ \\
$\quad$ Developmental dysplasia & $2(2)$ \\
$\quad$ Post-trauma & \\
Side - number (\%) & $46(49)$ \\
$\quad$ Right & $47(51)$ \\
$\quad$ Left & $84(90)$ \\
Surgical approach - number (\%) & $9(10)$ \\
$\quad$ Posterior &
\end{tabular}

Table II. Rates of wear and orientation of the acetabular component

\begin{tabular}{lc}
\hline $\begin{array}{l}\text { Measurable femoral head penetration - number (\%) } \\
\text { Yes }\end{array}$ & $89(96)$ \\
No & $4(4)$ \\
Median linear wear rate in mm per yr (range) & $0.18(0$ to 0.45$)$ \\
Median volumetric wear rate in $\mathrm{mm}^{3}$ per yr (range) & $103(0$ to 277) \\
Mean femoral head centre for operated hip (mm) & \\
$\quad$ Horizontal (SD) & $31.0(4.9)$ \\
$\quad$ Vertical (SD) & $15.9(4.7)$ \\
Mean femoral head centre for contralateral hip (mm) & \\
$\quad$ Horizontal (SD) & $32.0(5.1)$ \\
$\quad$ Vertical (SD) & $15.0(3.7)$ \\
Inclination angle in number of hips (\%) & \\
$\quad<35^{\circ}$ & $21(23)$ \\
$35^{\circ}$ to $55^{\circ}$ & $68(73)$ \\
$>55^{\circ}$ & $4(4)$ \\
\hline
\end{tabular}

post-operatively, and at three, six and nine years and the latest follow-up. The inclination angle of the acetabular component was measured as the angle between a horizontal line drawn through the interteardrop line and the inferior edge of the component. ${ }^{10}$ The height of the centre of the femoral head for both operated and non-operated sides was measured perpendicular to this interteardrop line. The horizontal position of the centre of the femoral head was measured perpendicular to the interteardrop line from the inferior point of the teardrop. ${ }^{11}$ Linear femoral head pene- tration and direction were measured according to the method described by Livermore, Ilstrup and Morrey ${ }^{12}$ on AP radiographs. A pair of compasses was used to establish the shortest distance from the centre of the femoral head to the edge of the acetabular component. Distances were measured to the nearest $0.1 \mathrm{~mm}$ using calipers, so that a wear of $\geq 0.1 \mathrm{~mm}$ was measurable. A wear rate of $\geq 0.2 \mathrm{~mm}$ per year was considered to be excessive. ${ }^{13}$ Volumetric wear was calculated by the formula $\mathrm{v}=\pi \mathrm{r}^{2} \mathrm{w}$, where $\mathrm{v}$ is the change in volume of the bearing, $r$ the radius of the femoral head and $\mathrm{w}$ the linear polyethylene wear measured. On all radiographs, the magnification was based on the size of the femoral head so that all measurements were individually corrected. Osteolysis was estimated in the three regions of the acetabular interface described by DeLee and Charnley ${ }^{14}$ and the proximal regions of the femur according to Gruen, McNiece and Amstutz. ${ }^{15}$ The presence of osteolysis on each radiograph was recorded before any measurements were taken, eliminating any observer bias.

All radiographic evaluations were undertaken by one independent observer (JHMG). Statistical analysis was performed using the SPSS statistical package (SPSS 11.0, Chicago, Illinois). The Wilcoxon signed rank test, MannWhitney $\mathrm{U}$ test, ANOVA test and linear regression were used. Significance was assumed when $\mathrm{p}<0.05$.

\section{Results}

The mean length of follow-up was 8.2 years ( 3 to 12 ) and the mean age at operation was 50 years (22 to 63). The mean pre-operative HHS of 55 (12 to 79) improved to 97 (44 to 100) by the latest follow-up of which the median pain subscore improved from 15 (10 to 30 ) to 43 (30 to 44 ).

The polyethylene wear of the femoral head, centre and acetabular positions are listed in Tables II and III. The median direction of penetration of the femoral head (according to Livermore et $\mathrm{al}^{12}$ ) during follow-up was $0^{\circ}$ (from $20^{\circ}$ laterally to $40^{\circ}$ medially). Compared with the contralateral side, the centre of the head on the operated side was equally positioned vertically $(\mathrm{p}=0.110)$ and horizontally ( $\mathrm{p}=0.209$ ). There was no correlation between the horizontal and vertical orientation of the centre of the head and the rate and direction of the polyethylene wear.

The inclination angle of the acetabular components was divided into three groups according to Sarmiento et al: ${ }^{16}$ $<35^{\circ}, 35^{\circ}$ to $55^{\circ}$ and $>55^{\circ}$. Sixty-eight $(73 \%)$ of the cups were positioned between $35^{\circ}$ and $55^{\circ}$ and no difference in the rate and direction of polyethylene wear could be estab-

Table III. Wear rates at different periods of follow-up

\begin{tabular}{|c|c|c|c|c|}
\hline & \multicolumn{4}{|c|}{ Periods of follow-up (yrs) } \\
\hline & 1 to 3 & 4 to 6 & 7 to 9 & $>9$ \\
\hline Number of THAs* & 93 & 83 & 71 & 24 \\
\hline Median linear wear rate in $\mathrm{mm}$ per yr (range) & $0.17(0$ to 0.67$)$ & 0.07 (0 to 0.63$)$ & $0.17(0$ to 1.40$)$ & $0.27(0$ to 2.11$)$ \\
\hline Median volumetric wear rate in $\mathrm{mm}^{3}$ per yr (range) & 113 (0 to 412$)$ & $41 \quad$ (0 to 388$)$ & $77 \quad(0$ to 862$)$ & (0 to 1298$)$ \\
\hline
\end{tabular}

*THA, total hip arthroplasty 
Table IV. Differences in the rates of median linear wear at different periods of follow-up in $\mathrm{mm}$ per year ( $p$ value ${ }^{*}$ )

\begin{tabular}{|c|c|c|c|c|}
\hline & \multicolumn{4}{|c|}{ Periods of follow-up (yrs) } \\
\hline & 1 to 3 & 4 to 6 & 7 to 9 & $>9$ \\
\hline \multicolumn{5}{|c|}{ Rates of wear (mm per yr) } \\
\hline 1 to 3 & - & $0.10(0.171)$ & $(0.326)$ & $0.10(0.021)^{\dagger}$ \\
\hline 4 to 6 & & - & $0.10(0.068)$ & $0.20(0.041)^{\dagger}$ \\
\hline 7 to 9 & & & - & $0.10(0.004)^{\dagger}$ \\
\hline$>9$ & & & & - \\
\hline
\end{tabular}

lished among the three groups $(\mathrm{p}=0.126$ and $\mathrm{p}=0.863$, respectively). Neither the HHS, nor the pain subscore, were related to the rate of linear polyethylene wear. The median rates of linear and volumetric polyethylene wear, measured at different follow-up periods are listed in Table III. The rate seen at four to six years was significantly lower $(\mathrm{p}=0.041)$ than after nine years of follow-up. Excessive polyethylene wear ( $\geq 0.20 \mathrm{~mm}$ per year) was seen in $45 \%$ of all THAs and in $70 \%$ of those followed up beyond nine years. Table IV lists the median individual differences in linear and volumetric polyethylene wear for the different follow-up periods. There was a statistically significant, higher wear rate after nine years than at the other follow-up periods. Osteolysis was seen in 18 THAs $(19 \%)$ at a mean follow-up of 8.2 years. According to the zones of DeLee and Charnley, ${ }^{14} 11$ THAs had osteolysis in zone I, three in zone II, three in zone III and one in all zones. No relationship was found with acetabular shell design or screw usage. Those THAs with a follow-up of $>9$ years in which osteolysis was seen had significantly higher median wear rates after nine years than the THAs without observable osteolysis $(0.66 \mathrm{~mm}$ per year 0 to 1.60$) v s 0.27 \mathrm{~mm}$ per year $(0$ to 2.11) $(p=0.029)$. No relationship was found between the rate of polyethylene wear and the other parameters of acetabular shell diameter, design or screw usage, polyethylene thickness, body mass index, gender, or femoral head material. Four prostheses dislocated, three in the first post-operative year and one in the eighth. No component required a revision. The survival of the acetabular components was $100 \%$ (95\% confidence interval (CI) 100). In a standard scenario, if all 29 THAs maintained their status before being lost to follow-up, the survival rate was 100\% (95\% CI 100), but in a worst case scenario (if all 29 THAs failed), this was reduced to $75 \%$ (95\% CI 74 to 76 ).

\section{Discussion}

A few studies, each with different results, have reported on the rate of polyethylene wear and its relationship with time after implantation for air-sterilised, polyethylene acetabular liners. ${ }^{4-8}$ Kurtz et $\mathrm{al}^{8}$ observed a progression of mechanical degradation with increasing implantation time in 16 air-sterilised polyethylene retrievals after a mean of 11.5 years. There was a statistically significant relationship with the oxidation index. The authors suggested that dissolved oxygen from body fluids diffused into the polyethylene component and reacted with residual free radicals from gamma sterilisation, a process probably comparable with shelf aging. The highest rates of mechanical degradation were recorded in the surface region of the polyethylene. In our study, the rate of wear increased significantly after nine years. Typical, although not statistically significant, was the relative reduction in wear at four to six years post-operatively in our study $(p=0.171)$. Other radiographic wear studies have suggested that the rate of wear decreases with implantation time. ${ }^{4-6}$ Isaac et $\mathrm{al}^{6}$ attributed their results to a rapid, irrecoverable deformation process (creep) followed by a steady, lower penetration rate associated with wear. We saw a similar transition in our study, but the rate of wear increased significantly after nine years.

This creep-to-steady state transition was not supported by Gomez-Barrena et al. ${ }^{7}$ Puolakka et $\mathrm{al}^{13}$ observed an excessive wear rate ( $\geq 0.20 \mathrm{~mm}$ per year) in $42 \%$ of their cases after a six-year follow-up, similar to our study. In $70 \%$ of our THAs with a follow-up beyond nine years the rate of wear was excessive, with a wide range of up to 2.11 $\mathrm{mm}$ per year. Our findings suggest that the rate of wear of the acetabular components is acceptable for the first nine post-operative years and excessive after that, with an unexplained wide range.

Hirakawa et $\mathrm{al}^{11}$ reported a higher inclination angle for those acetabular components which needed revision and a high correlation with the direction of polyethylene wear. Del Schutte et al ${ }^{17}$ failed to demonstrate any such correlation, a finding which is supported by the results of our study.

Schmalzried et $\mathrm{al}^{18}$ observed a statistically significant relationship between polyethylene wear and the centre of rotation. Hirakawa et $\mathrm{al}^{11}$ established a significant relationship between horizontal orientation of the centre of the head and the direction of polyethylene wear. Those acetabular components which showed laterally-directed wear were more medialised than those with medially-directed wear. However, we found no relationship between the rate of wear and either the vertical or horizontal orientation of the femoral head.

In support of work by Bono, Sanford and Toussaint, ${ }^{19}$ we showed higher rates of wear in patients with osteolysis beyond nine years of follow-up. Maloney et $\mathrm{al}^{20}$ reported 
acetabular osteolysis in 11 of 15 patients with a multi-holed acetabular shell, while Puolakka et $\mathrm{al}^{13}$ showed a higher rate of wear in acetabular components which required additional screw fixation. Meanwhile, Schmalzried et $\mathrm{al}^{21}$ found no direct correlation between the presence of screw holes or screws and the incidence of pelvic osteolysis, a finding which is supported by our results. The acetabular components which we used have a locking mechanism which might offer better rotational stability and minimise backside polyethylene wear and osteolysis. ${ }^{22}$

Metal-backed acetabular components were introduced because of findings which suggested that a more efficient stress transfer might delay loosening and migration. ${ }^{23}$ However, clinical studies observed the opposite and identified a $37 \%$ higher rate of wear for cemented metal-backed acetabular components than for non-metal-backed components in cemented THA. ${ }^{24}$ Many studies into the wear of uncemented metal-backed acetabular components and 28-mm femoral heads have been performed and have shown a polyethylene wear rate between 0.11 and $0.30 \mathrm{~mm}$ per year. ${ }^{13,24-28}$ These results are comparable with our own. We also agree with Yamamoto et $\mathrm{a}^{29}$ who found no relationship between polyethylene wear, polyethylene thickness, and age at operation after a mean follow-up of six years in 45 acetabular components with the same design of insert as used by ourselves.

In the mid-1990s sterilisation methods changed from gamma irradiation in air to, predominantly, irradiation in either an inert gas or vacuum packaging. Mechanical in vivo degradation after implantation, which is based on an oxidative mechanism, is higher in air gamma-sterilised than in argon gamma-sterilised polyethylene acetabular components. ${ }^{30}$

Highly cross-linked polyethylene shows an $80 \%$ to $90 \%$ wear reduction in hip simulator testing ${ }^{31}$ and a $31 \%$ reduction in a bilateral study of 32 patients after a mean followup of two years. ${ }^{32}$ We expect in future that better polyethylene quality will decrease the rate of wear and the prevalence of periprosthetic osteolysis in the mid to long term.

Other bearing materials, such as metal-on-metal or ceramic-on-ceramic, show significantly less third-body wear and periprosthetic tissue reaction than metal-on-polyethylene designs. Some authors have, therefore, concluded that second-generation all-metal implants should be considered in patients with a long life expectancy. ${ }^{33-35}$ Ceramics are hard and strong, highly resistant to chemical and mechanical dissolution, but also brittle. ${ }^{36}$ Hard-on-hard couples of metal-on-metal and ceramic-on-ceramic reduce wear to $0.001 \mathrm{~mm}$ per year ${ }^{37}$ but can lead to high-impact loading of the acetabulum, leading to stress shielding and fractures of the periprosthetic bone.

In conclusion, penetration rates of the femoral head into the polyethylene liner of the acetabular component are variable. Typically, there is a temporary reduction four to six years after implantation which can be explained by the transition from the deformation (creep) phase to a genuine polyethylene wear thereafter. A significant, increased rate of polyethylene wear can be seen after nine years of implantation, created by a mechanical degradation of the polyethylene surface. It is this category of patient which should be closely monitored for the rate of linear wear, osteolysis and loosening of the acetabular component.

No benefits in any form have been received or will be received from a commercial party related directly or indirectly to the subject of this article.

\section{References}

1. Malchau H, Herberts $\mathbf{P}$, Ahnfelt C. Prognosis of total hip replacement in Sweden: follow-up of 92,675 operations performed 1978-1990. Acta Orthop Scand 1993;64: 497-506.

2. Harris WH. The problem is osteolysis. Clin Orthop 1995;311:46-53

3. Willert HG, Buchhorn GH, Hess T. The significance of wear and material fatigue in loosening of hip prostheses. Orthopade 1989;18:350-69 (in German).

4. Charnley J, Cupec Z. The nine and ten year results of the low-friction arthroplasty of the hip. Clin Orthop 1973;95:9-25.

5. Charnley J, Halley DK. Rate of wear in total hip replacement. Clin Orthop 1975;112: $170-9$

6. Isaac GH, Dowson D, Wroblewski BM. An investigation into the origins of timedependent variation in penetration rates with Charnley acetabular cups: wear, creep or degradation? Proc Inst Mech Eng (H) 1996;210:209-16.

7. Gomez-Barrena E, Li S, Furman BS, et al. Role of polyethylene oxidation and consolidation defects in cup performance. Clin Orthop 1988;352:105-17.

8. Kurtz SM, Hozack W, Marcolongo M, et al. Degradation of mechanical properties of UHMWPE acetabular liners following long-term implantation. J Arthroplasty 2003; 18:68-78.

9. Harris WH. Traumatic arthritis of the hip after dislocation and acetabular fractures: treatment by mold arthroplasty. J Bone Joint Surg [Am] 1969;51-A:737-55.

10. Sellers RG, Lyles D, Dorr LD. The effect of pelvic rotation on alpha and theta angles in total hip arthroplasty. Cont Orth 1988;17:67-70.

11. Hirakawa K, Mitsugi N, Koshino T, et al. Effect of acetabular cup position and orientation in cemented total hip arthroplasty. Clin Orthop 2001;388:135-42.

12. Livermore J, Ilstrup D, Morrey B. Effect of femoral head size on wear of the polyethylene acetabular component. J Bone Joint Surg [Am] 1990;72-A:518-28.

13. Puolakka TJS, Laine HJ, Moilanen TPS, Koivisto AM, Pajamäki KJJ. Alarming wear of the first-generation polyethylene liner of the cementless porous-coated Biomet universal cup: 107 hips followed for mean 6 years. Acta Orthop Scand 2001; 72:1-7.

14. DeLee JG, Charnley J. Radiological demarcation of cemented sockets in total hip replacement. Clin Orthop 1976;121:20-32.

15. Gruen TA, McNiece GM, Amstutz HC. "Modes of failure" of cemented stem type femoral components: a radiographic analysis of loosening. Clin Orthop 1979;141: 17-27

16. Sarmiento A, Ebramzadeh E, Gogan WJ, McKellop HA. Cup containment and orientation in cemented total hip arthroplasties. J Bone Joint Surg [Am] 1990;72-A: 996-1002.

17. Del Schutte H Jr, Lipman AJ, Bannar SM, et al. Effects of acetabular abduction on cup wear rates in total hip arthroplasty. J Arthroplasty 1998;13:621-6.

18. Schmalzried TP, Shepher EF, Dorey FJ, et al. Wear is a function of use, not time. Clin Orthop 2000;381:36-46.

19. Bono JW, Sanford L, Toussaint JT. Severe polyethylene wear in total hip arthroplasty. J Arthroplasty 1994;9:119-25.

20. Maloney WJ, Peters P, Engh CA, Chandler H. Severe osteolysis of the pelvic in association with acetabular replacement without cement. J Bone Joint Surg [Am] 1993:75-A:1627-35

21. Schmalzried TP, Brown IC, Amstutz HC, Engh CA, Harris WH. The role of acetabular screw holes and/or screws in the development of pelvic osteolysis. Proc Inst Mech Eng (H) 1999;213:147-53.

22. Postak PD, Tradonsky S, Froimson AI, Greenwald AS. Performance characteristics of two piece acetabular cups: series II [abstract]. Orthop Trans 1996;20:182-3.

23. Carter DR, Vasu R, Harris WH. Stress distributions in the acetabular region. II: effects of cement thickness and metal backing of the total hip acetabular component. J Biomech 1982;15:165-70.

24. Cates HE, Faris PM, Keating EM, Ritter MA. Polyethylene wear in cemented metal-backed acetabular cups. J Bone Joint Surg [Br] 1993;75-B:249-53.

25. Devane PA, Bourne RB, Rorabeck CH, MacDonald S, Robinson EJ. Measurement of polyethylene wear in metal-backed acetabular cups. Clin Orthop 1995;319: 317-26. 
26. Hozack WJ, Rothman RH, Eng K, Mesa J. Primary cementless hip arthroplasty with a titanium plasma sprayed prosthesis. Clin Orthop 1996;333:217-25.

27. Kim YH, Kim JS, Cho SH. Primary total hip arthroplasty with a cementless porouscoated anatomical total hip prosthesis: 10- to 12-year results of prospective and consecutive series. J Arthroplasty 1999;14:538-48

28. Thanner $\mathbf{J}$. The acetabular component in total hip arthroplasty: evaluation of different fixation principles. Acta Orthop Scand Supp/ 1999;286:1-41

29. Yamamoto K, Imakure A, Shishido T, et al. Cementless total hip arthroplasty using porous-coated Biomet acetabular cups (Hexloc and Ringloc types). J Orthop Sci 2003:8:657-63.

30. Kurtz SM, Rimnac CM, Bartel DL. Degradation rate of ultra-high molecular weight polyethylene. J Orthop Res 1997;15:57-61.

31. Bragdon CR, Jasty M, Muratoglu OK, O'Connor DO, Harris WH. Third-body wear of highly cross-linked polyethylene in a hip simulator. J Arthroplasty 2003;18. 553-61.
32. Digas G, Karrholm J, Thanner J, Malchau H, Herberts P. Highly cross-linked polyethylene in total hip arthroplasty: randomized evaluation of penetration rate in cemented and uncemented sockets using radiostereometric analysis. Clin Orthop 2004;429:6-16.

33. Doorn PF. Wear and biological aspects of metal on metal total hip replacements Thesis. Nijmegen, The Netherlands: University Medical Center, Nijmegen, 2000:13.

34. Jacobsson SA, Djerf K, Wahlstrom $\mathbf{0}$. Twenty-year results of McKee-Farrar versus Charnley prostheses. Clin Orthop 1996;329(Suppl):60-8.

35. Schmalzried RP, Szuszczewicz ES, Akizuki KH, Petersen TD, Amstutz HC. Factor correlating with long term survival of McKee-Farrar to hip prostheses. Clin Orthop 1996;329(Suppl):48-59.

36. Willmann G. The evolution of ceramics in total hip replacement. Hip Int 2000;10 193-203.

37. Konttinen YT, Zhao D, Beklen A, et al. The microenvironment around total hip replacement prostheses. Clin Orthop 2005;430:28-38. 